\title{
Control of Human B Cell Tumor Growth in Severe Combined Immunodeficiency Mice by Monoclonal Anti-B Cell Antibodies
}

\author{
A. Durandy, ${ }^{*}$ N. Brousse, ${ }^{*}$ F. Rozenberg, ${ }^{5}$ G. De Saint Basile, * A. M. Fischer," and A. Fischer ${ }^{*}$ \\ ${ }^{*}$ Institut National de la Santé et de la Recherche Médicale, U 132, Hôpital des Enfants-Malades, 75015 Paris, France; ${ }^{\ddagger}$ Service \\ d'Anatomopathologie, Hôpital des Enfants-Malades, 75015 Paris, France, ${ }^{\S}$ Laboratoire de Virologie, Hôpital Saint-Vincent-de-Paul, \\ 75014 Paris, France; and "Laboratoire d'Hématologie, Hôpital des Enfants-Malades, 75015 Paris, France
}

\begin{abstract}
Severe combined immunodeficiency (scid) mice develop EBV $(+)$ B cell tumors after infusion of $\operatorname{EBV}(+)$ B cells or of $B$ cells and EBV. In this study, scid mice were infused with $B$ cell lines derived from three patients who developed a $B$ lymphocyte proliferative disorder after bone marrow or organ transplantation. Intraperitoneal injection of $5 \times 10^{6} \mathrm{~B}$ cells induced tumor growth in all mice, leading to death within 60 d. Human $B$ cells were identified in spleen and bone marrow by means of immunofluorescence or EBV genome amplification, and human IgM was detected in serum. Infusion of murine monoclonal antibodies specific for human B cell membrane antigens CD21, CD24, and CD23 was effective in $80 \%$ of animals, against two of the three cell lines preventing tumor development or inducing remission according to the time of treatment.

The effect was antibody dose dependent and was optimal with four intravenous infusions of at least $0.1 \mathrm{mg} 4 \mathrm{~d}$ apart. Human IgM in serum and human $B$ cells in spleen and bone marrow became undetectable when peritoneal tumors regressed completely. Infusions of IgG1 isotype-matched antiCD4 antibody or anti-CD3 antibody had no effect. Tumors developed or recurred in $50 \%$ of these animals injected with one of the $B$ cell line 3 mo after treatment was stopped.

The same anti-CD21 and anti-CD24 antibodies had been used to treat the three patients, and shown similar degrees of effectiveness as in the scid mouse model. These results indicate that scid mice may be suitable for assessing therapeutic approaches to human B cell proliferation. (J. Clin. Invest. 1992. 90:945-952.) Key words: severe combined immunodeficiency mice • B lymphoproliferative syndrome • B lymphoid cell lines •
\end{abstract} Epstein Barr virus • anti-B cell monoclonal antibodies

\section{Introduction}

Transformation of human lymphocytes by Epstein-Barr virus leads to B cell activation and indefinite B cell proliferation. In immunosuppressed patients, infection by EBV (particularly type 1 ) can lead to uncontrolled polyclonal or monoclonal proliferation. Such B lymphocyte proliferative disorders (BLPD) ${ }^{1}$

Address correspondence to Anne Durandy, M. D., INSERM U 132, Hôpital des Enfants-Malades, 149 rue de Sevres, 75015 Paris, France. Received for publication 16 January 1992 and in revised form 7 April 1992.

1. Abbreviations used in this paper: BLPD, B lymphocyte proliferative disorder; IF, immunofluorescence; LCL, lymphoid cell line; PCR, polymerase chain reaction; scid, severe combined immunodeficiency.

J. Clin. Invest.

(C) The American Society for Clinical Investigation, Inc.

0021-9738/92/09/0945/08 $\$ 2.00$

Volume 90, September 1992, 945-952 are a significant complication of the immunosuppression required for HLA nonidentical bone marrow and organ transplantation (1-4). BLPD also occur in HIV-infected subjects and patients with profound, primary $T$ cell disorders $(5,6)$. The outcome of BLPD is frequently poor, although some forms resolve following reduction of immunosuppression therapy (7), and treatment with the antiviral drug DHPG (8) or $\alpha$ 2-interferon plus immunoglobulin $:(9)$. We have recently found that nonmonoclonal BLPD can be controlled by the administration of CD21 - and CD24-specific monoclonal antibodies (10).

Severe combined immunodeficiency (scid) mouse T and B lymphocytes are unable to differentiate because of a defective recombinase complex and thus exhibit a profound immunodeficiency $(11,12)$; this has enabled several groups to transplant human lymphoid cells $(13,14)$. EBV-infected B cells grow well in scid mice and give rise to tumors (15-18), and their morphological and membrane characteristics are identical to those of EBV-induced B cell lines in vitro and some EBV-induced BLPD in immunosuppressed patients. Lymphocytes containing the EBV genome $(15,16)$, lymphocytes injected before Epstein-Barr virus infection (17) and B lymphoblastoid cell lines can also grow in scid mice (18). To determine whether scid mice were suitable as an in vivo model for screening potential anti-BLPD treatments, we inoculated scid mice with EBVinduced $B$ cell lines from three immunodeficient patients who had developed BLPD. We then tested the effectiveness of murine anti-human B cell antibodies in arresting B cell tumor growth.

\section{Methods}

scid mice. 4- to 6-wk-old CB17 scid/scid mice were purchased from Iffa-Credo (L'Arbresle, France) or were a kind gift from Dr. J. L. Guénet (Institut Pasteur, Paris, France). The immunological defect was confirmed in each animal by a blood lymphocyte count $<100 / \mu \mathrm{l}$. The mice were kept in a sterile isolator and received three nonabsorbable antibiotics (colimycin, tobramycin, and vancomycin) in sterile water.

Monoclonal antibodies and immunofluorescence studies. The following murine monoclonal antibodies directed against various human antigens were used to treat scid mice: anti-CD21 (IOB1a-IgG1), antiCD24 (IOB3-IgG1), anti-CD23 (IOB8-IgG1) (all three from Immunotech, Marseille-Luminy, France), anti-CD3 (OKT3-IgG2a) (Ortho Pharmaceutical, Raritan, NJ) and anti-CD4 (BF5-IgG1 from Dr. Widjenes, Centre Regional de Transfusion Sanguine, Besançon, France).

The following $\mathrm{mAb}$ (Immunotech) against human cell surface antigens were used in immunofluorescence (IF) studies. Anti-CD21 (IOB1a), anti-CD24 (IOB3), FITC-anti-CD19 (IOB4-IgG1), FITCanti-CD23 (IOB8-IgG1), FITC-anti-CD18 (IOT8-IgG1): mAb against human immunoglobulin heavy chains $(\mu, \delta, \gamma, \alpha)$ and light chains $(\kappa$ and $\lambda$ ) were purchased from Caltag Laboratories (South San Francisco, CA ). A two-step immunofluorescence assay using an FITClabeled goat anti-mouse immunoglobulin (GAMIG; Caltag) was used 
for staining with unlabeled antibodies. Analysis was performed using a Facscan $^{\otimes}$ (Becton Dickinson and Co., Mountain View, CA). Membrane immunofluorescence studies were performed on cell suspensions. Mouse organs (liver, spleen, and bone marrow) were homogenized and filtered, and mononuclear cells were isolated on density gradients (Lymphoprep; Nuyagaard, Oslo, Norway). Peritoneal cells were obtained by gentle washing of the peritoneal cavity.

Intracytoplasmic immunoglobulin content was assessed by means of direct immunofluorescence using FITC-labeled anti-human heavy or light chain antibodies, on smears of fixed cells that were examined under a Leitz microscope.

Immunohistology. Fragments of abdominal tumors were snap frozen in isopentane in liquid nitrogen. Cryostat sections $5-\mu \mathrm{m}$ thick were placed on glass sides, air dried for at least $2 \mathrm{~h}$, fixed in acetone for 10 min, and stored at $-20^{\circ} \mathrm{C}$ until use. Other fragments were fixed in Bouin's solution and embedded in paraffin. Sections $2 \mu \mathrm{m}$ thick were stained with hematoxylin and eosin. A three-stage indirect immunoperoxidase method (19) was applied to cryostat sections, which were incubated with $\mathrm{mAb}$ directed against human lymphoid $\mathrm{B}$ cells and EBV antigens. The following $\mathrm{mAb}$ were used: anti-CD19 (B4 IgG1; Coulter Corp., Hialeah, FL), anti-CD20 (B1, IgG2; Coulter), antiCD21 (BL13-IgG1; Immunotech), anti-CD22 (IgG2b, DakoPatts Glostrup, Copenhagen, Denmark), anti-CD23 (IOB8-IgG1; Immunotech), anti-CD24 (ALB9-IgG1; Immunotech), anti-human heavy $\mu$ chain (IgG1; DakoPatts), anti-K (IgG1; Coulter) and $\lambda$ (IgGI; Coulter) human light chains. mAb against membrane-associated EBV antigens (EBV-MA, IgG1; Clonatec, Paris, France) or nuclear antigens (EBV-NA, IgG1; Clonatec) were also used.

The mAb Ki67 (DakoPatts) was used to label cells entering the cell cycle. The following two $\mathrm{mAb}$ were used to detect mouse-derived cells: anti-lyt2 (TIB 105, IgG2a [American Type Culture Collection; Rockville, MD) and anti-CR3 (5C6 IgG1; Cell-Tech, Slough, Berkshire, UK).

$E B V$ genome detection by means of the polymerase chain reaction $(P C R)$. The Epstein-Barr virus genome was detected using the PCR. Mononuclear cell suspensions obtained from mouse organs were lysed, and either directly used for PCR, or subjected to DNA extraction. Approximately 150,000 nucleated cells, or $2 \mu \mathrm{g}$ of DNA, were used for amplification. The oligonucleotide primers were chosen in a highly specific region of the DNA polymerase gene of herpesviruses. The amplified products were detected and analyzed by means of gel electropho-

Table I. Characteristics of LCL

\begin{tabular}{lccc}
\hline & \multicolumn{3}{c}{ LCL } \\
\cline { 2 - 4 } & 48 & 41 & 22 \\
\hline Surface markers (\%) & & & \\
$\quad$ sIgM & 97 & 90 & 65 \\
IgD & 95 & $<1$ & 28 \\
IgG & $<1$ & $<1$ & 12 \\
sIgA & $<1$ & $<1$ & 13 \\
$\kappa$ & $<1$ & 80 & 29 \\
$\lambda$ & 96 & 11 & 53 \\
CD19 & 99 & 96 & 85 \\
Cytoplasmic production & IGM $\lambda$ & IGM $\kappa$ & IGM $\kappa+\lambda$ \\
EBV antigen expression & & & \\
EBV NA* & + & + & + \\
EBV MA* & + & + & + \\
Immunogenotype & & & \\
H & $3 R^{\ddagger}$ & $4 R$ & $5 R$ \\
$\kappa$ & $1 \mathrm{R}$ & $3 R$ & $2 R$ \\
$\lambda$ & $2 R$ & $2 R$ & $3 R$ \\
\hline
\end{tabular}

* EBV NA, EBV nuclear-associated antigens; EBV MA, EBV membrane-associated antigens. ${ }^{\ddagger} R$, rearranged immunoglobulin band. resis and further characterized using restriction enzyme analysis, as previously described (20). Each round of PCR included internal, positive, and negative controls.

Serum immunoglobulin determination. Human IgM immunoglobulin was determined in mouse serum by means of nephelometry using an anti-human-IgM antibody. Monoclonal immunoglobulin was identified using the Paragon immunofixation electrophoresis kit (Beckman Instruments, Inc., Fullerton, CA) according to the method described by Ritchie (21).

$48 \mathrm{~h}$ after the second injection of anti-CD21 mAb $(0.1 \mathrm{mg}$ intravenously), anti-CD21 levels in mouse serum were determined using IF with an FITC-Gamig on a B lymphoid cell line; serum from untreated mice and unlabeled $\mathrm{mAb}$ were used as controls.

Rearrangement of immunoglobulin genes. Total genomic DNA was extracted from each of the three B cell lines (LCL). $10 \mu \mathrm{g}$ of DNA was digested to completion with EcoRI, HindIII, or BamHI + HindIII restriction endonucleases. Fragments were size-fractionated by electrophoresis on $0.9 \%$ agarose gels and blotted onto nylon filters (Hybond $\mathrm{N}$ Plus; Amersham, Les Ulis, France) in $0.4 \mathrm{M} \mathrm{NaOH}$. Probes labeled radioactively by random priming were used to hybridize the filter in $50 \%$ formamide at $42^{\circ} \mathrm{C}$ overnight. Washings were done sequentially down to $0.1 \times$ standard saline citrate- $0.1 \%$ SDS. The probes used were the $\mathrm{JH}(2.2 \mathrm{~kb}, \operatorname{San} 3 \mathrm{~A})$, and $\mathrm{Jk}(2 \mathrm{~kb}$, SatI $)$ genomic probes from $\mathrm{P}$. Leder, Harvard Medical School, Boston, MA $(22,23)$. The IgC $\lambda$ genomic probe was the $3.5 \mathrm{~kb}$ EcoRI-HIndIII fragment containing $C \lambda 2$ $\left(\mathrm{kerm}^{-} \mathrm{OZ}^{-}\right)(24)$.

B lymphoid cell lines. Three B lymphoblastoid cell lines were spontaneously grown from the blood of three children who developed a lymphoproliferative syndrome after immunosuppressive therapy of heart allograft rejection episodes in two cases (LCL 48 and 41) and HLA-unidentical bone marrow transplantation in the third (LCL 22). The three patients received same therapeutic protocol using anti-B cell monoclonal antibodies anti-CD21 and anti-CD24. The patients from whom the cell lines (BLCL) 48 and 22 were derived were cured but the patient from whom BLCL 41 was derived died rapidly from the disease progression (25).

The characteristics of the B cell lines are described in Table I. LCL 48 expressed membrane $\operatorname{IgM} \lambda$ and $\operatorname{IgD}$ and synthesized $\operatorname{IgM} \lambda$, as
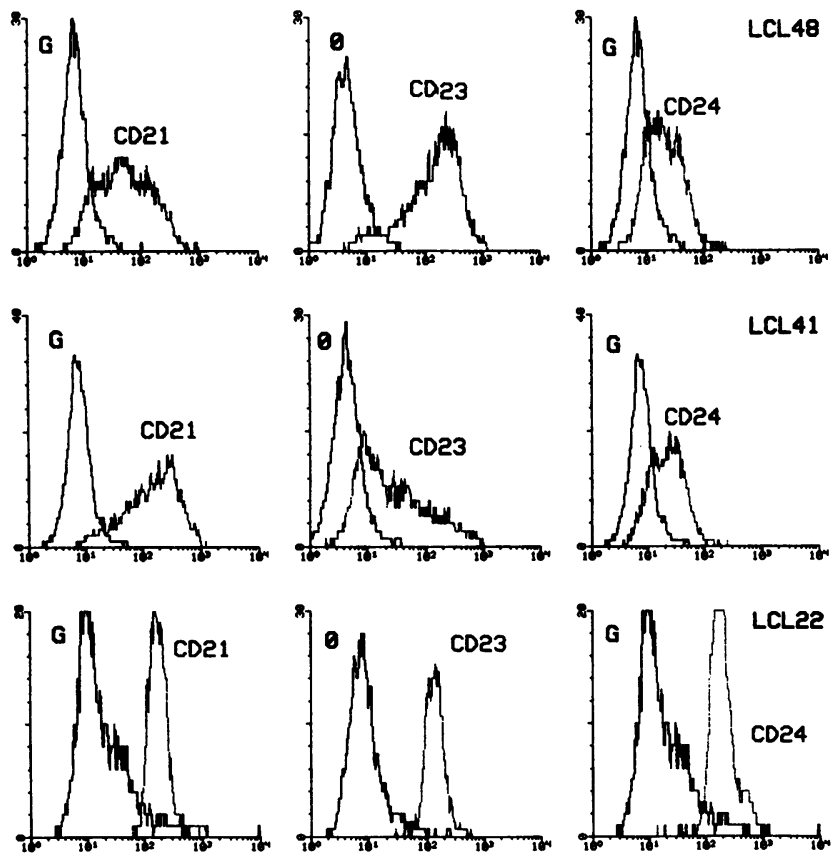

Figure 1. Membrane expression of CD21 (BL13 + Gamig), CD23 (FITC-IOB8), and CD24 (ALB9 + Gamig) on LCL 48, 41, and 22. $(O)$ Control without MAb; $(G)$ Gamig alone. 

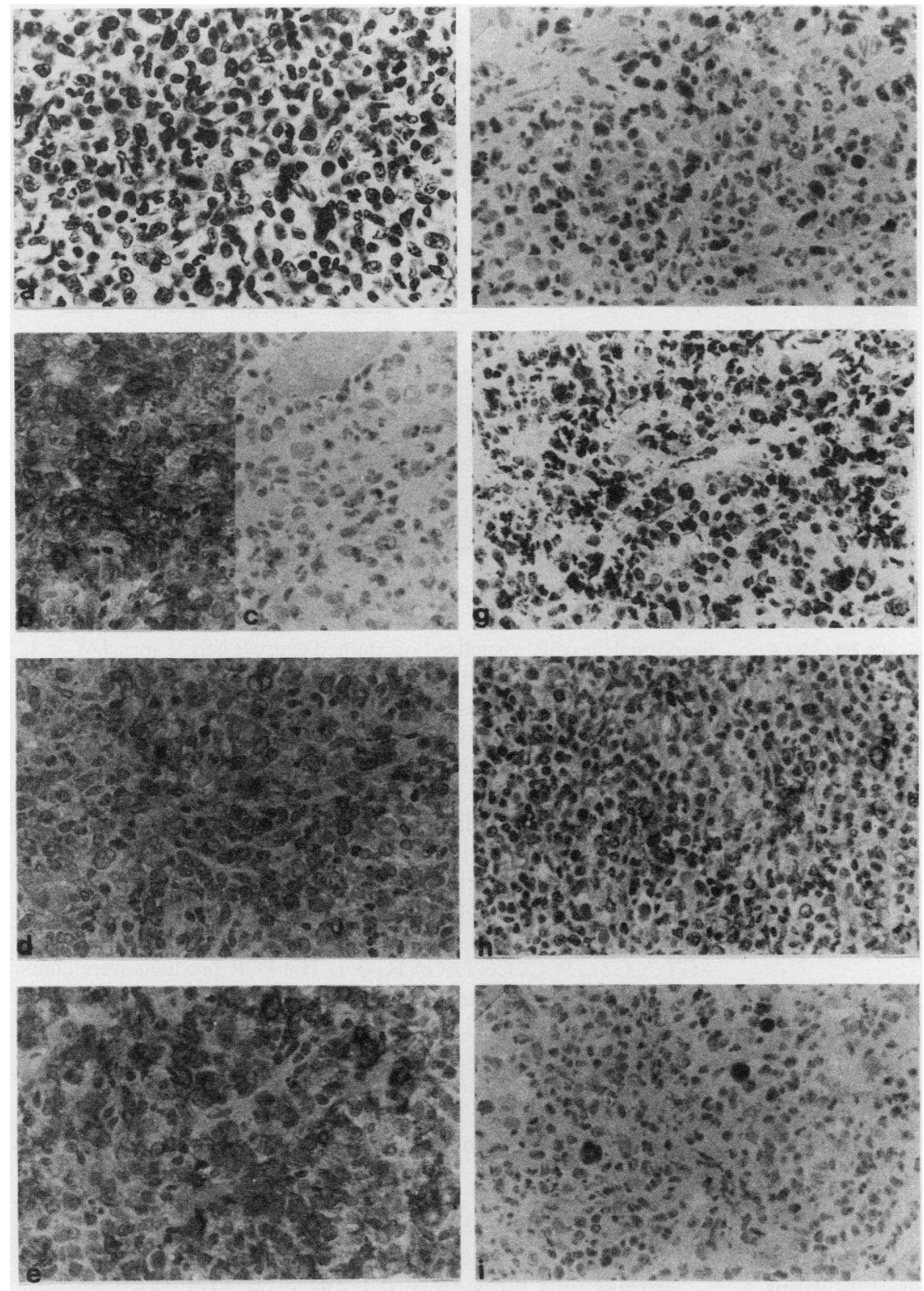

Figure 2. Immunohistochemical characteristics of an abdominal human B cell tumor (LCL 48) in scid mice: the lymphoid proliferation is diffuse with areas of necrosis $(a)$. Tumor cells are strongly stained with monoclonal antibodies directed against lambda light chain $(b), \operatorname{CD} 19(d)$, and CD21 (e). Kappa light chain is not expressed $(c)$. Most cells are labeled with $\mathrm{Ki67}$ antibody $(f)$. Murine $\mathrm{CR} 3^{+}$macrophages are intermingled with lymphoid cells $(g)$. EBV membrane antigens $(h)$ and nuclear antigens $(i)$ are strongly detected. Three-step indirect immunoperoxidase technique applied to frozen sections. $\times 250$. shown by the detection of cytoplasmic IF. LCL 41 expressed only IgM, with principally $\kappa$ light chain on the membrane and cytoplasmic $\operatorname{IgM} \kappa$. LCL 22 expressed membrane IgM and IgD, together with lower levels of $\operatorname{IgG}$ and $\operatorname{IgA}$, with expression of $\kappa$ and $\lambda$ light chains; both $\operatorname{IgM} \kappa$ and $\lambda$ were present in the cytoplasm. As shown in Table I, the study of immunoglobulin gene rearrangements showed the presence of predominant clones, with $\kappa$ and/or $\lambda$ light-chain gene rearrangements in the three LCL. The presence of minor clones comprising $<5 \%$ of the B cell population cannot be excluded. The membrane expression of CD21, CD23, and CD24 by the three LCL is depicted in Fig. 1; special attention was paid to their relative degrees of expression because the corresponding antibodies were to be infused.

All three LCL were EBV-induced, as indicated by concomitant seroconversion to anti-EBV IgM in two patients and the detection of EBV antigens (EBNA and EBMA) by means of histoimmunochemistry in all three.

LCL karyotyping revealed no consistent abnormalities.

\section{Results}

Growth of LCL 48 in scid mice. 6-wk-old scid mice were injected intraperitoneally with various numbers of LCL 48 cells.
All the animals that received at least $5 \times 10^{6}$ cells developed macroscopic abdominal tumors from day 20 onward, leading to death in every case before day $60.5 \times 10^{6} \mathrm{LCL} 48$ were thus used in subsequent experiments. At day 30 to 40 , mice developed hind-leg paralysis, urine retention, and enteric obstruction. Tumor nodules $(3 \mathrm{~cm})$ were detectable in mesenteric and retroperitoneal areas, with enlargement of mesenteric lymph nodes in $25 \%$ of cases and of the spleen in $50 \%$.

Tumor cells recovered from the animals showed identical characteristics to those grown in vitro. They were labeled with mAb against human B cell antigens (CD19, CD21, CD23, $\mathrm{CD} 24$, and CD18) and expressed membrane $\operatorname{IgM} \lambda$, with intracytoplasmic IgM $\lambda$ in nearly all cells (not shown). Histologic studies of the abdominal tumors showed diffuse proliferation and large areas of necrosis. The cells were polymorphic and consisted mainly of large lymphoid cells with numerous atypical cells and murine CR3(+) macrophages. Histoimmunochemistry confirmed the findings obtained with membrane immunofluorescence on cell suspensions. Tumor cells were strongly 


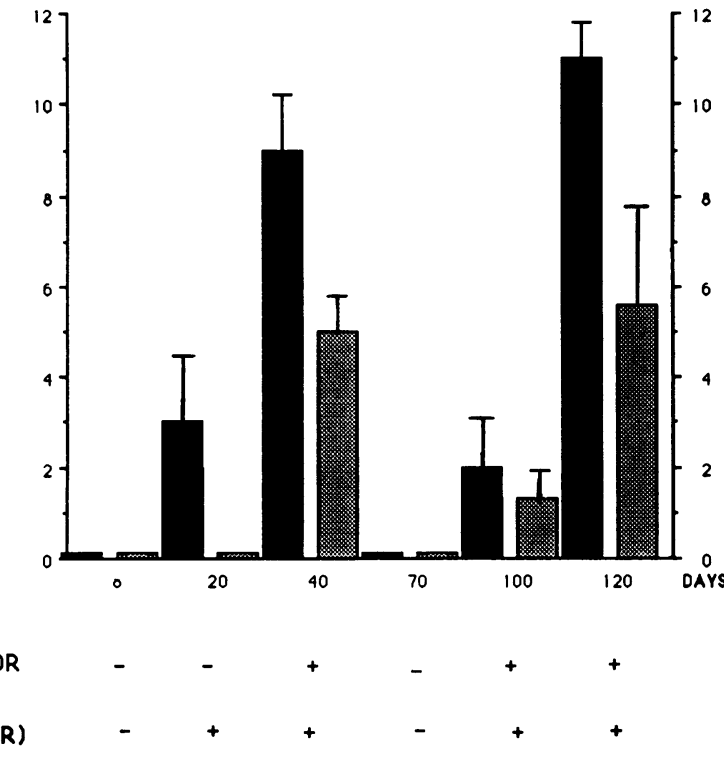

Figure 3. Sequential study of scid mice after inoculation of LCL 48 ( 5 $\times 10^{6}$ cells $)$ at day 0 , treatment by anti-CD21 mAb $(0.1 \mathrm{mg} \mathrm{IV} \times 4$ from day 30 to 42 ), and recurrence of tumors leading to death at day 120. The percentage of CD19 in the spleen $(n=5)$, is shown, with EBV genome positivity. Human $\operatorname{IgM}$ was measured in serum $(n=2)$. -, $\mathrm{CD} 19(\%)$; $\mathbf{m}, \operatorname{IgM}(\mathrm{g} / \mathrm{liter})$.

stained with mAb to CD19, CD21, CD23, and CD24, and with MAb to $\mu$ heavy and $\lambda$ light chains. EBV antigens were also strongly detected (Fig. 2).

IF studies of spleen cell suspensions from mice killed at various times indicated that human $\mathrm{CD} 19(+)$ B lymphocytes could be detected as early as 20 days after LCL 48 inoculation, representing $\sim 3 \%$ of mononuclear spleen cells. This figure reached $11 \%$ at the time of onset of the macroscopic abdominal tumors (day 30 to 40) (Fig. 3). No human B cells were detected in liver or bone marrow by means of IF. However, PCR gave evidence of the presence of $\operatorname{EBV}(+)$ cells in spleen and bone marrow as early as 20 days after LCL inoculation (Figs. 3 and 4 ). This technique was very sensitive since, in serial dilutions of LCL 48 cells added to normal mice spleen cells, a positive signal could be obtained with one $\mathrm{EBV}^{+}$cell in $10^{5}$ mice cells.

High levels of human IgM $(5.3 \mathrm{mg} / \mathrm{ml})$ were found at the time of tumor detection: immunofixation revealed a monoclonal human $\operatorname{IgM} \lambda$ component (data not shown).

Treatment of scid mice with anti-human B cell monoclonal antibodies. Groups of at least 10 mice inoculated with $5 \times 10^{6}$ LCL 48 cells were given various treatments.

Mice were treated from day 30 after LCL inoculation to day 42 by anti-CD21 MAb at various dosages $(0.001 \mathrm{mg}-0.5 \mathrm{mg})$ and by two different routes, as follows: intravenously, four injections every $4 \mathrm{~d}$, and intraperitoneally, 12 daily injections. As shown in Fig. 5, CD21-specific antibody infusions delayed death. Intravenous treatment was the most efficient. Infusions of $0.1 \mathrm{mg}$ or $0.5 \mathrm{mg}$ of anti-CD21 MAb delayed death by at least $80 \mathrm{~d}$ and no tumor was detected during the survival period. Tumors recurred around day 100-120 in half the mice, giving a final survival rate of $40 \%$ at day 175 in mice treated with four infusions of $0.1 \mathrm{mg}$ anti-CD21 MAb. Infusion of a lower dosage of antibody had an intermediate effect, although some mice survived tumor free for at least 6 mo (Fig. 5). Intra-

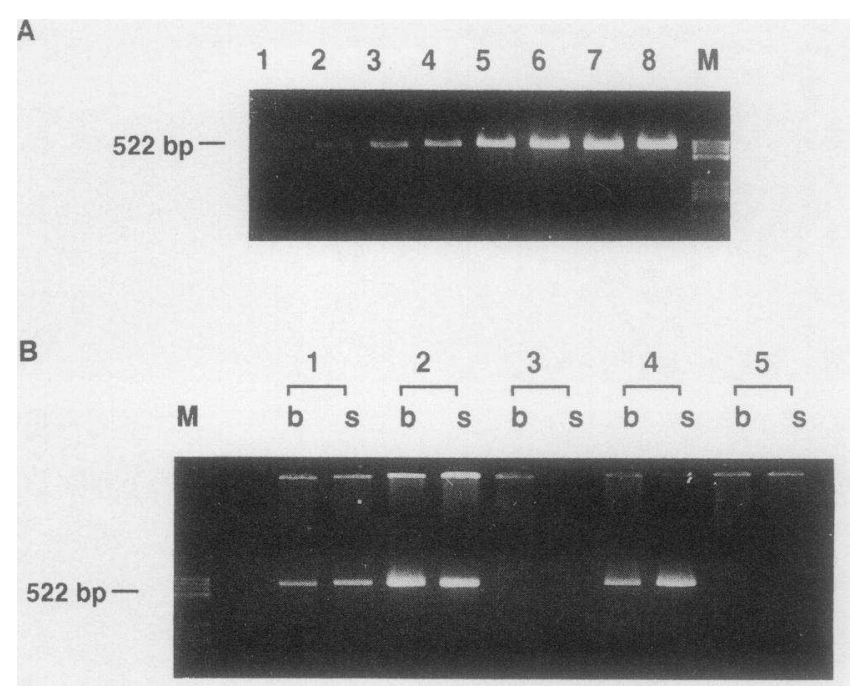

Figure 4. (A) Sensitivity analysis of PCR assay. DNA amplification of serial dilutions of $\mathrm{EBV}^{+}$tumor cells added to $1.5 \times 10^{3}$ spleen mononuclear cells, visualized on stained agarose gels. Lanes 1-8: $<1$, $1,2,10,20,100.200$, and 1,000 tumor cells, respectively. (B) Detection of $\mathrm{EBV}^{+}$tumor cells in murine tissues. Scid mice were inoculated peritoneally with LCL 48 on day 0 . Mice $(n=12)$ were killed at various times before and after anti-CD21 MAb treatment. EBV ${ }^{+}$ human B cells were detected in bone marrow $(b)$ and spleen $(s)$ by using PCR to amplify a fragment of the EBV DNA polymerase gene. Each PCR reaction was performed on DNA obtained from one mouse, and constantly reproduced when repeated. A fragment of the DNA polymerase gene of EBV was amplified by PCR by using primers: P1 (5'-(GACTTTGCCAGCCTGTACC-3') P2 (5'AGTCCGTGTCCCCGTAGATG-3'). The PCR products were characterized with reference to their specific molecular masses ( $522 \mathrm{bp}$ ), and restriction profile with restriction enzymes, as previously reported. Lanes $1,2,3,4$, and 5 correspond to days $20,40,60,100$, and 200 , respectively. The mouse killed on day 100 had an abdominal tumor, while the mouse killed on day 200 had no detectable tumor. $M$, size marker generated by HaeIII digestion of pBR 322 .

peritoneal injection ( $0.1 \mathrm{mg}$ daily) of anti-CD21 MAb also had an effect on survival, although all mice died by day 120 .

Intravenous infusion of $0.1 \mathrm{mg}$ anti-CD21 MAb on four occasions was used in subsequent experiments. As early as $24 \mathrm{~h}$ after the first infusion of anti-CD21 MAb, tumor cells were strongly stained with Gamig alone, giving evidence of the accessibility of B cells to the CD21 MAb in vivo. The anti-CD21 $\mathrm{MAb}$ concentration in serum was evaluated in binding experiments with LCL 48 . The serum antibody concentration was $10-25 \mu \mathrm{g} / \mathrm{ml}$ in treated mice after the second intravenous injection. Histoimmunochemical studies of the tumor showed infiltration by murine CR3 $(+)$ polymorphonuclear cells and macrophages, with no detectable murine $\mathrm{CD} 8(+)$ cells (Fig. 2).

To assess the specificity of the treatment, animals were treated with other anti-human B cell antibodies of the same IgG1 isotype (anti-CD23 and anti-CD24). A comparable effect on survival was obtained likely because LCL 48 expresses CD21, CD23, and CD24 membrane antigens (Fig. 6). A control anti-CD3 MAb and an isotype-matched anti-CD4 MAb had no blocking effect on LCL growth or an effect on survival.

Recurrence of tumors in treated mice. The macroscopic tumors disappeared in a few days when the anti-CD21 MAb was administered from day 30 to 42 . Human IgM was no longer 


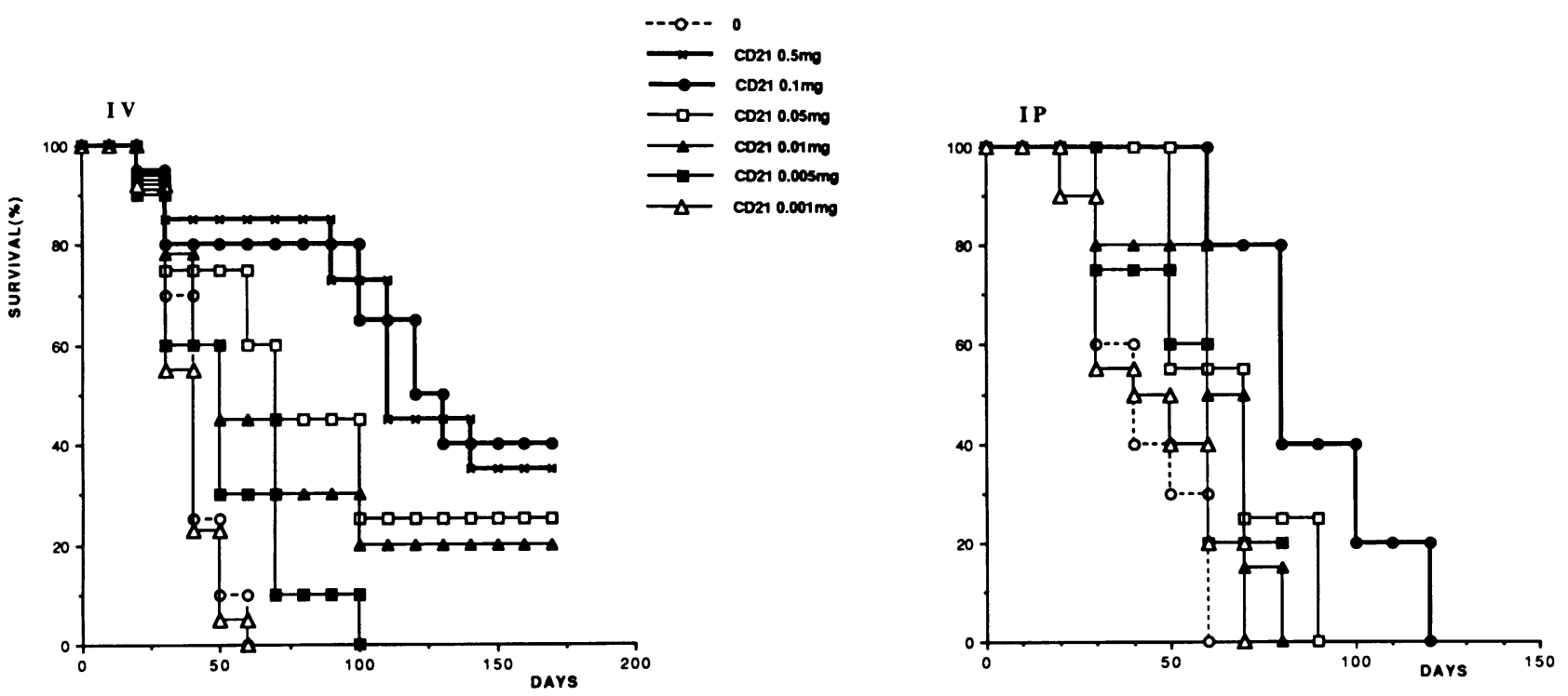

Figure 5. Dose-dependent response to treatment with anti-CD21 MAb infused intravenously (IV) (4 injections at day 30, 34, 38, and 42), or intraperitoneally $(I P)$ ( 12 daily injections from day 30 to 42). Each group consisted of 10 mice.

detectable at day 50, and human CD19(+) B cells were absent from the spleen. The EBV genome could not be detected in spleen, bone marrow (Fig. 3), liver, or the peritoneal cavity. However, the sequential study showed a recurrence of human $\mathrm{CD} 19(+) \mathrm{B}$ cells in the spleen $(3 \%)$, confirmed by EBV genome detection, in half the mice, and a reappearance of human $\operatorname{IgM}$ in the serum $(3 \mathrm{mg} / \mathrm{ml})$ at day 100 , preceding the recurrence of macroscopic tumors; the mice died at about day 120 (Fig. 5). In nonrelapsing mice, no human B lymphocytes were detected by immunofluorescence or by PCR amplification and human IgM was undetectable in the serum 200 days after inoculation. Survival was not associated with the emergence of a leaky phenotype since a very small number of $\mathrm{T}$ cells was found in the spleen.

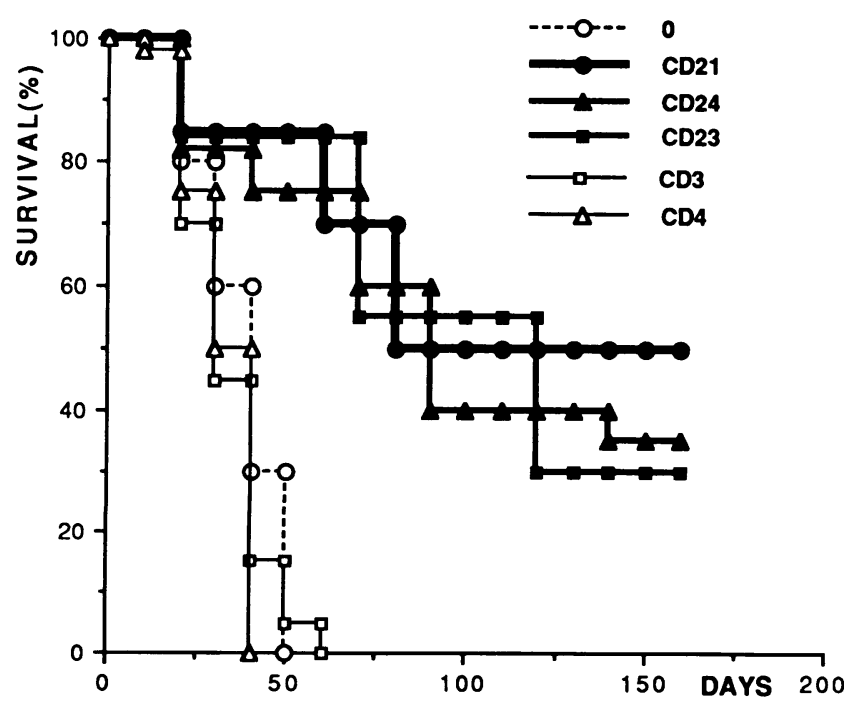

Figure 6. Specificity of anti-human B cell MAb (anti-CD21, CD23, $\mathrm{CD} 24)$ of the IgG1 isotype as compared with irrelevant $\mathrm{mAb}(\mathrm{CD} 3$, IgG2a, and CD4 IgG1). All MAb were infused intravenously $(4 \times 0.1$ $\mathrm{mg}$ ) between days 30 and 42 . Each group consisted of 10 mice.
The recurrence of B cell tumor growth was not accounted for by phenotypic alterations, since the B cells still expressed CD21, CD23, and CD24 (data not shown). Earlier treatment of mice after B cell inoculation was associated with less frequent relapse and better survival, as shown in Fig. 7 for mice treated from day 20 onward.

Sensitivity of the three LCL to anti-CD21 MAb. To evaluate the efficacy of anti-CD21 MAb treatment on the growth of the LCL, $5 \times 10^{6}$ cells from LCLs 22 and 41 were inoculated into groups of scid mice which were then treated with anti$\mathrm{CD} 21$ or anti-CD23 mAb: the results were compared to those for mice inoculated with LCL 48. The characteristics of the LCLs are described in Table I and in Fig. 1.

All three LCL developed into tumors in scid mice, leading to death in every case. Administration of anti-CD21 or antiCD23 mAb (0.1 mg intravenously from day 30 to 42 ) gave different results according to the LCL. Mice which received

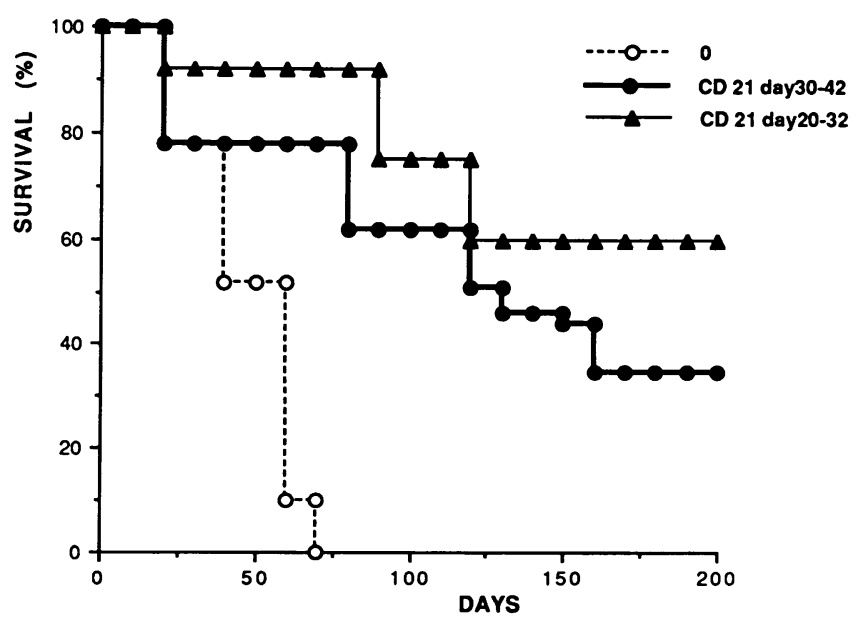

Figure 7. Response of scid mice to anti-CD21 MAb treatment (4 $\times 0.1 \mathrm{mg}$ intravenously) infused from days $30-42$ or days $20-32$. Each group consisted of 10 mice. 

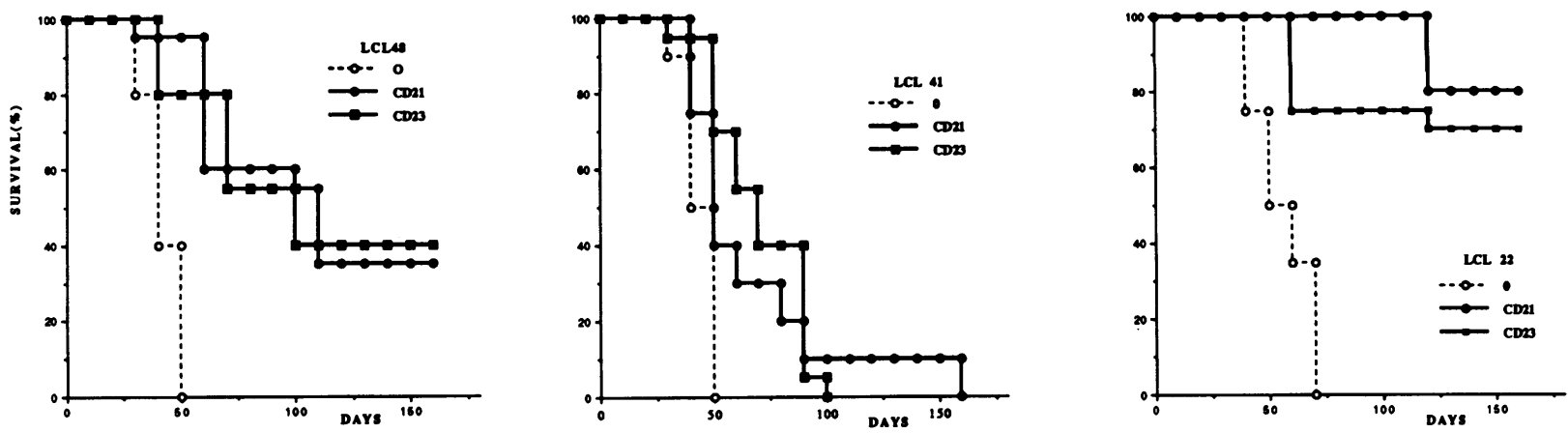

Figure 8. Different sensitivities of the three LCL to anti-CD21 MAb $(4 \times 0.1 \mathrm{mg}$ intravenously from days $30-42)$. Each group consisted of $10 \mathrm{mice}$.

LCL 22 showed the best response to treatment, with $80 \%$ survival at day 160 , and no detectable human B cells. In contrast, mice inoculated with LCL 41 showed a poor response to treatment ( $10 \%$ survival at day 100 ; Fig. 8 ), although the LCL was stained by the anti-CD21 and anti-CD23 mAb in an immunofluorescence study (Fig. 1). The failure of treatment could not be related to a CD21 modulation since the tumor cells recovered at day 50 strongly expressed CD21 antigens. However, they only exhibited IgM K immunoglobulins without detectable $\lambda$ light chains (Fig. 9).

\section{Discussion}

This study shows that murine anti-human B cell monoclonal antibodies can block EBV-induced human B cell growth in scid mice. Uncontrolled proliferation of EBV-transformed B cells can occur in scid mice leading to rapid tumor development and death (15-18): this phenomenon can be induced by intravenous or intraperitoneal injection of either $\operatorname{EBV}(+)$ peripheral blood lymphocytes (PBL) (16), EBV (-) PBL + EB virus (15, 17), B lymphoblastoid cell lines established in vitro (16), or B cell lymphomas (18). We have set up a similar model on the basis of EBV-related BLPD that developed in immunosuppressed patients as polyclonal, oligoclonal, or monoclonal B cell proliferations $(10,25)$. As in previous models, B cells recovered from the tumors in scid mice had similar membrane phenotype characteristics to those growing in vitro. BLCL growth in scid mice after intraperitoneal injection was again similar to what has been observed in the other models, i.e., intraperitoneal tumor development with some infiltration of the spleen
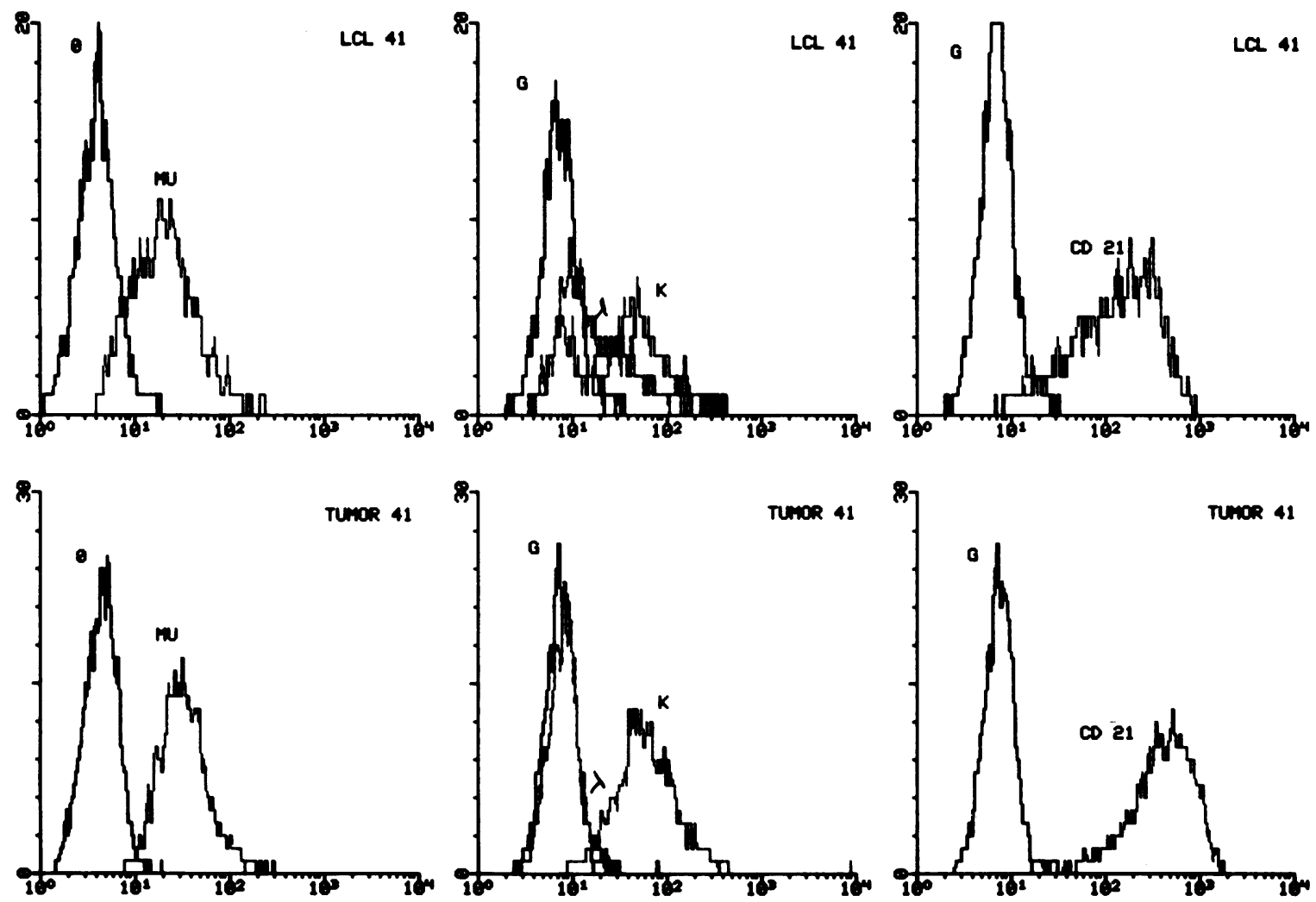

Figure 9. Membrane expression of IgM, $\kappa$, and $\lambda$ light chains and of CD21 on LCL 41 and on tumor 41 cells recovered from scid-mice after treatment by CD21 MAb (day 50). (O) Control without MAb; $(G)$ Gamig alone. 
and bone marrow (18). A monoclonal human IgM component was found in large quantities in the scid mouse serum.

Three anti-B cell monoclonal antibodies specific for distinct membrane molecules (CD21, CD23, and CD24) were able to induce tumor regression: a dose-effect relationship was established for the anti-CD21-specific antibody. Intravenous infusion was more efficient than the intraperitoneal route, possibly because of better distribution within extracellular spaces. Dosages of $0.1 \mathrm{mg}$ per infusion and above led to tumor-cell membrane saturation and excess anti-CD21-specific mAb in serum, suggesting that higher dosages were not required. Indeed, four infusions of 0.1 or $0.5 \mathrm{mg}$ gave similar results. Anti$B$ cell antibody treatment resulted in tumor shrinkage and a rapid disappearance of human IgM and human B cells, as shown by CD19 mAb staining of spleen cells and EBV amplification in spleen and bone marrow. However, as relapses occurred, a small number of human B cells probably escaped the treatment, even undetectable by EBV amplification though the threshold of detection was one tumor cell per $1.5 \times 10^{5}$ normal mouse spleen cells.

The specificity of the antibody treatment was shown by the lack of effect of unrelated murine anti-human-T cell antibodies of identical (IgG1) and different (IgG2a) isotypes. That anti-B cell $\mathrm{mAb}$ of the same isotype but with distinct specificities can similarly block B cell proliferation in vivo strongly suggests that they share a common mechanism of action, i.e., opsonization of B cells leading to phagocytosis or antibody-dependent killing (26). This was suggested by murine polymorphonuclear cell and monocyte infiltration of the tumors. Furthermore, the antibodies used were unable to block B cell proliferation in vitro and did not bind complement. Further work will be required $(a)$ to assess the precise mechanism by which they induce cell death in vivo and $(b)$ to compare the potential efficiency of B cell-specific antibodies of other isotypes.

Two other findings call for comment in the light of the use of such antibodies to treat B cell lymphoproliferative disorders in man, the different sensitivities of distinct B cell LCL to anti$B$ cell antibody therapy and the frequent occurrence of relapse in scid mice.

We found no correlation between the degree of CD21 membrane expression and anti-CD21 antibody efficiency in the three LCL. LCL 41 was poorly sensitive to anti-CD21 MAb, whereas B LCL 22 growth was arrested. Refractoriness was not associated with CD21 modulation. Similar results were observed in the corresponding patients who were treated intravenously with anti-CD21 + anti-CD24 antibodies (25), suggesting that the different cell lines have different cell division kinetics. Lower expression of CD23 by LCL 41 might participate to the more malignant phenotype.

The $\mathrm{B}$ cell tumors frequently recurred after effective treatment with anti-CD21,-CD23, or -CD24 antibodies. The recurrent tumor cells exhibited the same phenotypic characteristics (particularly membrane antigen expression) as the original tumor cells, indicating that relapses were not due to cells resistant to therapy. Recurrence could be accounted for by the persistence of a very small number of LCL B cells which continue to expand in the absence of immunocompetent cells. This is supported by the lower relapse rate in mice treated before the onset of detectable tumors, i.e., those with a more limited B cell tumor burden. Prevention of relapse in these mice could also be mediated by additional human B cell killing by natural killer cells, which can elicit bone marrow graft rejection in scid mice
$(27,28)$. These results apparently contrast with the infrequent recurrence of B LPD in man after efficient treatment with antiCD21- and CD24-specific antibodies: such recurrences have only been observed in two out of patients with persistent profound immunodeficiency (25). They also reinforce the hypothesis that residual $\mathrm{B}$ cells are killed by nonspecific or EBVspecific cytotoxic cells in these patients (5).

Our results also show that scid mice can be used as an in vivo model for screening agents potentially active on BLCL growth, since there was a good correlation between the clinical and experimental data. Questions regarding antibody specificity, isotype, combinations of antibodies, the infusion protocol, the positive or negative role of cytokines such as IFN $\alpha(9,29)$ and IL-6 $(30,31)$, together with that of murine and human cytotoxic cells, remain to be addressed. Schmidt-Wolf et al. have shown that ex vivo treatment of bone marrow from scid mice contaminated by human lymphoma $B$ cells with nonspecific cytotoxic T cells prevents human B cell lymphoma development in scid mice (18). Similar in vivo studies are now underway to assess whether cytotoxic cells ( specific and nonspecific) can control the growth of residual B cells after antibody treatment.

\section{Acknowledgments}

We would like to thank Dr. M. Prieur for karyotype analysis, Dr. F. Le Deist for helpful advice, Mrs. M. Forveille and M. Leborgne for excellent technical assistance, Mrs. D. Bresson for typing the manuscript, and Mrs. E. Coudrier and C. Tourneau for the skillful care of the scid mice colonies.

We are indebted to Dr. M. Hirn (Immunotech, Marseille, France) and to Dr. Robinson (Celltech, Slough, UK) for the generous gift of $\mathrm{mAb}$, and to Dr. J. L. Guénet (Institut Pasteur, Paris, France) for providing scid mice.

\section{References}

1. Hanto, D. W., G. Frizzera, J. Gaji-Peckzalska, and R. L. Simmons. 1985. Epstein-Barr virus, immunodeficiency and B cell proliferation. Transplantation (Baltimore). 39:461-472.

2. Frizzera, G., D. W. Hanto, and J. Gaji-Peczalska. 1981. Polymorphic diffuse B cell hyperplasias and lymphomas in renal transplant recipients. Cancer Res. 41:4262-4279.

3. Schubach, W. H., G. Miller, and E. D. Thomas. 1985. Epstein-Barr virus genomes are restricted to secondary neoplastic cells following bone marrow transplantation. Blood. 65:535-538.

4. Young, L., C. Alfieri, and K. Hennessy. 1989. Expression of Epstein-Barr virus transformation-associated genes in tissues of patients with EBV lymphoproliferative disease. N. Engl. J. Med. 321:1080-1085.

5. Birx, D. L., R. R. Redfields, and G. Tosato. 1986. Defective regulation of Epstein-Barr virus infection in patients with acquired immunodeficiency syndrome (AIDS) or AIDS-related disorders. N. Engl. J. Med. 314:874-879.

6. MacMahon, E. M. E., J. D. Glass, S. Diane-Hayward, R. B. Mann, P. S. Becker, P. Charache, J. C. McArthur, and R. F. Ambinder. 1991. Epstein-Barr virus in AIDS-related primary central nervous system lymphoma. Lancet. 338:969-973.

7. Ho, M., R. Jaffe, and G. Miller. 1988. The frequency of Epstein-Barr virus infection and associated lymphoproliferative syndrome after transplantation and its manifestations in children. Transplantation (Baltimore). 45:719-727.

8. Starzl, T. E., M. A. Nalesnick, and K. A. Porter. 1984. Reversibility of lymphomas after lymphoproliferative lesions developing under cyclosporin-steroid therapy. Lancet. i:583-587.

9. Shapiro, R. S., A. Chauvenet, and W. McGuire. 1988. Treatment of B-cell lymphoproliferatıve disorders with interferon alpha and intravenous gamma globulin. N. Engl. J. Med. 318:1334.

10. Blanche, S., F. Le Deist, F. Veber, G. Lenoir, A. M. Fischer, J. Brochier, C. Boucheix, M. Delaage, C. Griscelli, and A. Fischer. 1988. Treatment of severe Epstein-Barr virus-induced polyclonal B-lymphocyte proliferation by anti-B cell monoclonal antibodies. Ann. Intern. Med. 108:199-203.

11. Bosma, G. C., R. P. Custer, and M. J. Bosma. 1983. A severe combined immunodeficiency in the mouse. Nature (Lond.). 301:527-530.

12. Schuler, W., I. J. Weiler, A. Schuler, R. A. Philips, N. Rosenberg, T. W. 
Mak, J. F. Kearney, R. P. Perry, and M. J. Bosma. 1986. Rearrangement of antigen receptor genes is defective in mice with severe combined immune deficiency. Cell. 46:963-972.

13. Mosier, D. E., R. J. Gulizia, S. M. Baird, and D. B. Wilson. 1988. Transfer of a functional human immune system to mice with severe combined immunodeficiency. Nature (Lond.). 335:256-259.

14. Namikawa, R., K. N. Weilbaecher, H. Kaneshima, E. J. Yee, and J. M. McCune. 1990. Long-term human hematopoiesis in the SCID-hu mouse. J. Exp. Med. 172:1055-1063.

15. Cannon, M. J., P. Pisa, R. I. Fox, and N. R. Cooper. 1980. Epstein-Barr virus induces aggressive lymphoproliferative disorders of human $\mathrm{B}$ cell origin in SCID/hu chimeric mice. J. Clin. Invest. 85:1333-1337.

16. Rowe, M., I. S. Young, J. Crocker, H. Stokes, S. Henderson, and A. B. Rickinson. 1991. Epstein-Barr virus (EBV)-associated lymphoproliferative disease in the SCID mouse model: implications for the pathogenesis of EBV-positive lymphomas in man. J. Exp. Med. 273:147-158.

17. Okano, M., Y. Taguchi, H. Nakamine, S. J. Pirruccello, J. R. Davis, K. W. Beisel, K. L. Kleveland, W. G. Sanger, R. R. Fordyce, and D. T. Purtilo. 1990 Characterization of Epstein-Barr virus-induced lymphoproliferation derived from human peripheral blood mononuclear cells transferred to severe combined immunodeficient mice. Am. J. Pathol. 137:517-522.

18. Schmidt-Wolf, I. G. H., R. S. Negrin, H. P. Kiem, K. G. Blume, and I. L. Weissman. 1991. Use of a SCID mouse/human lymphoma model to evaluate cytokine-induced killer cells with potent antitumor cell activity. J. Exp. Med. 174:139-149.

19. Stern, H., B. Uchanska-Ziegler, J. Gerdes, A. Ziegler, and P. Wernet. 1982. Hodgkin and Sternberg-reed cells contain antigens specific to late cells of granulopoiesis. Int. J. Cancer. 29:283-290.

20. Rozenberg, F., and P. Lebon. 1991. Amplification and characterization of herpes virus DNA in cerebrospinal fluid from patients with acute encephalitis. $J$. Clin. Microbiol. 29:2412-2417.

21. Ritchie, R. F., and R. Smith. 1976. Immunofixation. I. General principles and application to agarose gel electrophoresis. Clin. Chem. 22:497-499.
22. Ravetch, J. V., U. Siebenlist, S. Korsmeyer, T. Waldmann, and P. Leder 1981. Structure of the human immunoglobulin $\mu$ locus: characterization of embryonic and rearranged $\mathrm{J}$ and $\mathrm{D}$ genes. Cell. 27:583-591.

23. Hieter, P. A., E. E. Max, J. G. Seidman, J. V. Maizel, Jr., and P. Leder. 1980. Cloned human and mouse kappa immunoglobulin constant and $\mathrm{J}$ region genes conserve homology in functional segments. Cell. 22:197-207.

24. Dariavach, P., G. Lefranc, and M.P. Lefranc. 1987. Human immunoglobulin $\mathrm{C} 6$ gene encodes the $\mathrm{Kern}{ }^{+} \mathrm{Oz}^{-}$chain and $\mathrm{C} 4$ and $\mathrm{C} 5$ are pseudogenes. Proc. Natl. Acad. Sci. USA. 84:9074-9078.

25. Fischer, A., S. Blanche, J. Le Bidois, P. Bordigoni, J. L. Garnier, P. Niaudet, F. Morinet, F. Le Deist, A. M. Fischer, C. Griscelli, and M. Hirn. 1991. Treatment of severe B lymphocyte proliferative syndrome occurring after marrow and organ transplantation with anti-B cell monoclonal antibodies. $N$. Engl. J. Med. 324:1451-1456.

26. Waldmann, T. A. 1991. Monoclonal antibodies in diagnosis and therapy. Science (Wash. DC). 252:1657-1663.

27. Dorshkind, K., S. B. Pollack, M. J. Bosma, and R. A. Phillips. 1985. Natural killer (NK) cells are present in mice with severe combined immunodeficiency (scid). J. Immunol. 134:3798-3801.

28. Fulop, G. M., and R. A. Phillips. 1986. Full reconstitution of the immune deficiency in scid mice with normal stem cells requires low-dose irradiation of the recipients. J. Immunol. 136:4438-4443.

29. Heslop, H. E., A. C. M. Bianchi, F. T. Cordingley, M. Turner, W. C. P. de Mel, A. V. Hoffbrand, and M. K. Brenner. 1990. Effect of interferon gamma on autocrine growth factor loops in B lymphoproliferative disorders. J. Exp. Med. 172:1729-1734.

30. Ambrus, J. L., Jr., and A. S. Fauci. 1985. Human B lymphoma cell line producing B cell growth factor. J. Clin. Invest. 75:732-735.

31. Scala, G., I. Quinto, M. R. Ruocco, A. Arcucci, M. Mallardo, P. Caretto, G. Forni, and S. Venuta. 1990. Expression of an exogenous interleukin 6 gene in human Epstein Barr virus B cells confers growth advantage and in vivo tumorigenicity. J. Exp. Med. 172:61-68. 